SOUZA, L.C.D. et al. Utilização de dejetos e resíduos de origem animal como alternativa na adubação de feijão irrigado. PUBVET, Londrina, V. 8, N. 4, Ed. 253, Art. 1674, Fevereiro, 2014.

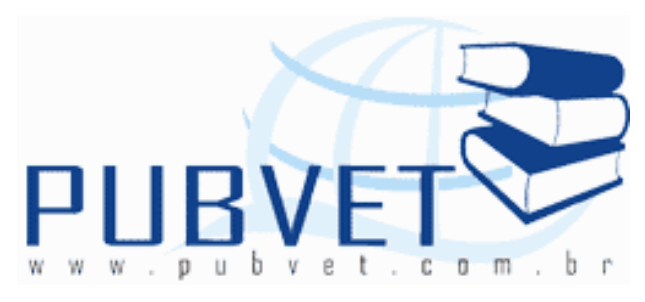

PUBVET, Publicações em Medicina Veterinária e Zootecnia.

\title{
Utilização de dejetos e resíduos de origem animal como alternativa na adubação de feijão irrigado
}

\footnotetext{
Lilian Christian Domingues de Souza ${ }^{1}$, Alício José Corbucci Moreira ${ }^{2}$, Neli Cristina Belmiro dos Santos ${ }^{3}$, Lauro Kenji Komuro ${ }^{4}$, Leandro Barradas Pereira ${ }^{5}$, Irlana Aparecida Lopes Pereira ${ }^{6}$
}

${ }^{1}$ Professora na Faculdades Integradas de Três-Lagoas-MS;

2 Pós-graduando na Faculdade de Medicina Veterinária de Araçatuba (FMVA UNESP);

${ }^{3}$ Pesquisadora da Agência Paulista de Tecnologia dos Agronegócios/Extremo Oeste em Andradina/SP;

${ }^{4}$ Professor na ETEC Sebastiana Augusta de Moraes, Andradina/SP;

${ }^{5}$ Professor na ETEC Sebastiana Augusta de Moraes, Andradina/SP;

${ }^{6}$ Estudante do Técnico em Agropecuária, ETEC Sebastiana Augusta de Moraes, Andradina/SP.

\section{Resumo}

O presente trabalho teve como objetivo avaliar diferentes tipos de adubação orgânica no desenvolvimento e produtividade da cultivar de feijão colibri no Município de Andradina-SP. O trabalho foi conduzido na área experimental da ETEC "Sebastiana Augusta de Moraes", situada no Município de Andradina, no ano de 2012. O delineamento experimental utilizado foi em blocos casualizados com quatro repetições, utilizando-se uma cultivar de feijão (colibri) e seis 
SOUZA, L.C.D. et al. Utilização de dejetos e resíduos de origem animal como alternativa na adubação de feijão irrigado. PUBVET, Londrina, V. 8, N. 4, Ed. 253, Art. 1674, Fevereiro, 2014.

tratamentos (testemunha, esterco bovino, esterco suíno, esterco de galinha, torta de filtro e adubo orgânico com silício). Conclui-se que a cultivar Colibri apresentou produtividade superior com a aplicação de fertilizante orgânico obtido a partir de resíduos de frigorífico e a combinação com silício.

Palavras-chave: Sustentabilidade; cultivares; adubação orgânica.

\title{
Using waste and leavings of animal origin as an alternative in fertilization of bean irrigated
}

\begin{abstract}
This study aimed to evaluate different types of organic fertilizers on the development and productivity of the cultivar hummingbird bean in the Municipality of Andradina-SP. The work was conducted in the experimental area of ETEC "Augusta Sebastiana de Moraes", located in the Municipality of Andradina, in the year 2012. The experimental design was a randomized block with four repetitions, using a bean cultivar (hummingbird) and six treatments (witness, cattle manure, pig manure, chicken manure, filter cake and organic fertilizer with silicon). It is concluded that the cultivar hummingbird presented higher productivity with the application of organic fertilizer obtained from slaughterhouse waste and combination with silicon.
\end{abstract}

Keywords: Sustainability, cultivars, organic fertilizer.

\section{INTRODUÇÃO}

O feijão é cultivado em todo o território nacional em diversos sistemas de produção, o que tem refletido em baixas produtividades. Assim o uso de compostos orgânicos tem-se intensificado, devido a necessidade de se aperfeiçoar as técnicas de cultivo e minimizar os impactos ambientais, causados pelo uso frequente de insumos químicos.

A baixa produtividade muitas vezes é atribuída a deficiências na adubação. No entanto, outras variáveis impactam diretamente na produção, dentre elas: 
SOUZA, L.C.D. et al. Utilização de dejetos e resíduos de origem animal como alternativa na adubação de feijão irrigado. PUBVET, Londrina, V. 8, N. 4, Ed. 253, Art. 1674, Fevereiro, 2014.

o uso de cultivares pouco produtivas, os efeitos desfavoráveis do solo, principalmente baixa fertilidade, pela expansão da cultura para áreas marginais, às condições adversas de clima e à incidência de pragas e doenças.

Silva (2005) relata que a área, produção e rendimento de feijoeiro cultivado sem o uso de insumos químicos artificiais têm aumentado, embora muito pequena, em relação ao cultivo convencional.

Desta forma a agricultura orgânica vem se destacando como um sistema de produção sustentável, baseado na preservação do ambiente e no respeito ao homem, defendendo a justiça econômica e social (SANTOS, 2011). As características da atividade incluem a manutenção da fertilidade do solo por meio de adubos verdes, compostos orgânicos, uso dos restos culturais, dejetos de animais, resíduos agroindustriais e adubos minerais de baixa solubilidade.

Freire et al. (2009) relataram que o uso de compostos orgânicos tem-se intensificado, devido a necessidade de se aperfeiçoar as técnicas de cultivo e minimizar os impactos ambientais, causados pelo uso freqüente de insumos químicos e da maior oferta pelas empresas que produzem os adubos orgânicos. Assim há necessidade de determinar as quantidades que proporcionem a melhor expressão do potencial dos novos cultivares que são lançados anualmente, com menor custo de produção.

Neste tipo de agricultura, predominam o controle biológico de insetos e a proibição ao uso de compostos sintéticos, como fertilizantes, pesticidas, herbicidas, reguladores de crescimento e aditivos alimentares para os animais.

Sendo a principal vantagem do cultivo orgânico a não utilização de agrotóxicos, que podem colocar em risco a saúde dos agricultores e do consumidor final e a redução de riscos de contaminação ambiental. Portanto, o objetivo desta pesquisa foi de avaliar diferentes tipos de adubação orgânica na cultura do feijoeiro, sendo fundamental para o desenvolvimento sustentável. 
SOUZA, L.C.D. et al. Utilização de dejetos e resíduos de origem animal como alternativa na adubação de feijão irrigado. PUBVET, Londrina, V. 8, N. 4, Ed. 253, Art. 1674, Fevereiro, 2014.

\section{MATERIAL E MÉTODOS}

O trabalho foi conduzido na área experimental da ETEC "Sebastiana Augusta de Moraes" situada no Município de Andradina Noroeste do Estado de São Paulo no ano de 2012. O clima é do tipo Aw, segundo a classificação de Köeppen, definido como tropical úmido com estação chuvosa no verão e seca no inverno.

O solo do local é considerado de acordo com a classificação da EMBRAPA (1999), como LATOSSOLO VERMELHO, distrófico típico argiloso.

Os tratamentos foram constituídos de 1 cultivar de feijão (Colibri) e seis tipos de adubos orgânicos (esterco bovino, esterco de suíno, esterco de galinha, torta de filtro, adubo orgânico com silício e a testemunha, sem nenhum tipo de adubo orgânico).

A cultivar de feijão colibri é do grupo carioca, de ciclo precoce e porte ereto feijão do grupo comercial carioca, ciclo de 67 dias, hábito de crescimento do tipo I (crescimento determinado), lançado pelo IAPAR (Instituto Agronômico do Paraná).

O delineamento experimental utilizado foi em blocos casualizados com quatro repetições. As parcelas experimentais foram constituídas por 4 linhas de $4 \mathrm{~m}$ de comprimento, utilizando-se como área útil, as 2 linhas centrais, desprezando-se 0,5 $\mathrm{m}$ das extremidades de cada linha.

A semeadura foi realizada no dia 22 de maio de 2012, manualmente no espaçamento de 0,45 m entre linhas, distribuindo-se 15 sementes por metro. A adubação de semeadura foi realizada aplicando-se $1800 \mathrm{~g} / \mathrm{rua}$ do adubo orgânico, ou seja, quatro toneladas por hectare e a adubação de cobertura foi realizado aos 35 dias após a semeadura.

Durante a condução do experimento no campo, a cultura do feijão será irrigada por aspersão, em toda a área, aplicando-se aproximadamente $15 \mathrm{~mm}$ de água por vez e irrigado duas vezes por semana.

As avaliações realizadas na ocasião da colheita foram a contagem das plantas de duas linhas centrais na área útil de cada parcela, totalizando 4,00 m 
SOUZA, L.C.D. et al. Utilização de dejetos e resíduos de origem animal como alternativa na adubação de feijão irrigado. PUBVET, Londrina, V. 8, N. 4, Ed. 253, Art. 1674, Fevereiro, 2014.

de linha da cultura, cujos valores foram utilizados para a obtenção do número de plantas correspondentes a um hectare.

Foram coletadas ao acaso 10 plantas de cada parcela onde foram avaliados:

I. Número médio de vagens por planta: foi obtido através da relação entre número total de vagens e número total de plantas, considerando as 10 plantas coletadas.

II. Número médio de grãos por planta: foi obtido através da relação entre número total de grãos por número total das 10 plantas coletadas.

III. Massa de 100 sementes: foi realizada de acordo com a metodologia adaptada das indicações das Regras de Análises de Sementes (BRASIL, 1992), pesando-se oito sub amostras de 100 sementes por tratamento em balança de precisão $(0,001 \mathrm{~g})$ e feita a correção para umidade à $13 \%$.

IV. Produtividade de sementes: a colheita do experimento será realizada manualmente em cada parcela, quando $95 \%$ das vagens apresentavam a coloração típica de vagem seca. As vagens serão debulhadas manualmente e as sementes limpas com auxílio de peneiras e acondicionadas em saco de papel, para posteriores pesagens da produção, determinação da umidade e cálculo da produtividade em $\mathrm{kg} \mathrm{ha}^{-1}$ a $13 \%$ de umidade (base úmida).

\section{RESULTADOS E DISCUSSÃO}

Os resultados obtidos nas avaliações estão apresentados na Tabela 1. Pelos dados analisados verificou-se que a cultivar colibri em sistema orgânico apresentou maior número de vagem/planta ${ }^{-1}$ no tratamento onde foi utilizado o adubo orgânico com silício, sendo observado o menor valor de vagens/planta ${ }^{-1}$ na testemunha $\left(4,20\right.$ vagens/planta $\left.{ }^{-1}\right)$.

Para a variável analisada grãos/planta ${ }^{-1}$ o tratamento orgânico com silício apresentou 36,63 grãos/planta ${ }^{-1}$, diferindo-se dos demais tratamentos. 
SOUZA, L.C.D. et al. Utilização de dejetos e resíduos de origem animal como alternativa na adubação de feijão irrigado. PUBVET, Londrina, V. 8, N. 4, Ed. 253, Art. 1674, Fevereiro, 2014.

Em relação a massa de 100 grãos $(\mathrm{g})$, os dados foram significativos para o tratamento esterco bovino, esterco de galinha e adubo orgânico com silício diferindo-se da testemunha.

Para produtividade de grãos $\left(\mathrm{kg} / \mathrm{ha}^{-1}\right)$ o destaque foi para o tratamento de adubo orgânico com silício apresentado uma produtividade de $1.316 \mathrm{~kg} / \mathrm{ha}^{-1}$, diferindo-se do tratamento de esterco suíno que apresentou uma produtividade de $989 \mathrm{~kg} / \mathrm{ha}^{-1}$ e a testemunha com uma produtividade de $840 \mathrm{~kg} / \mathrm{ha}^{-1}$, sendo que os demais tratamentos apresentaram produtividade semelhante a do tratamento adubo orgânico com silício.

Esses resultados de produtividade foram inferiores aos resultados encontrados em sistema orgânico em virtude do estresse hídrico sofrido pela cultura pela falta de irrigação na fase de enchimento de grãos. Santos (2011) relatam que a produtividade da cultura IAC Alvorada na região noroeste do estado de São Paulo em sistema de cultivo orgânico atingiu uma produtividade de $2.290 \mathrm{~kg} / \mathrm{ha}^{-1}$. Pereira (1984) obteve um aumento na produtividade de feijão com o uso de doses crescentes de composto orgânico, combinado com adubo mineral. Ferreira et al. (2008) que verificaram produtividades menores nos tratamentos somente com o adubo orgânico.

Tabela 1. Médias de número de vagens $^{-1}$, número de grãos planta ${ }^{-1}$, massa de 100 grãos ( $\mathrm{g}$ ) e produtividade $\left(\mathrm{kg} \cdot \mathrm{ha}^{-1}\right)$.

\begin{tabular}{|c|c|c|c|c|}
\hline Tratamentos & Vagens planta $^{-1}$ & Grãos planta $^{-1}$ & $\begin{array}{l}\text { Massa de } 100 \\
\text { grãos (g) }\end{array}$ & $\begin{array}{c}\text { Produtividade } \\
\left(\mathrm{kg}^{\left.-\mathrm{ha}^{-1}\right)}\right)\end{array}$ \\
\hline T1 & $4,20 \mathrm{c}$ & $16,2 \mathrm{c}$ & $18,9 \mathrm{c}$ & $840 c$ \\
\hline T2 & 5,45 b & $23,2 \mathrm{~b}$ & $23,8 \mathrm{a}$ & $1.093 a b$ \\
\hline T3 & $5,15 \mathrm{~b}$ & $23,7 \mathrm{~b}$ & $21,8 \mathrm{ab}$ & 989 c \\
\hline T4 & $5,65 \mathrm{~b}$ & 26,4 & $24,6 a$ & $1.130 \mathrm{ab}$ \\
\hline T5 & $5,35 \mathrm{~b}$ & $23,2 \mathrm{~b}$ & $22,3 \mathrm{ab}$ & $1.096 a b$ \\
\hline T6 & $8,65 a$ & $36,6 a$ & $26,5 a$ & $1.316 \mathrm{a}$ \\
\hline Médias & 5,74 & 25,00 & 23,00 & 306,00 \\
\hline \multicolumn{5}{|c|}{$\begin{array}{l}\text { T1 - Testemunha, T2 - Esterco bovino, T3 - Esterco suino, T4 - Cama de Frango, T5 - Torta de filtro, T6 - Adubo } \\
\text { orgãnico + Silício. }\end{array}$} \\
\hline & $\begin{array}{l}\text { Progra } \\
\text { variáveis for }\end{array}$ & $\begin{array}{l}\text { atístico utilizado } \\
\text { bmetidas ao test }\end{array}$ & ey a $5 \%$. & \\
\hline
\end{tabular}


SOUZA, L.C.D. et al. Utilização de dejetos e resíduos de origem animal como alternativa na adubação de feijão irrigado. PUBVET, Londrina, V. 8, N. 4, Ed. 253, Art. 1674, Fevereiro, 2014.

\section{CONCLUSÕES}

A partir dos resultados obtidos concluiu-se que o cultivar Colibri apresentou produtividade superior com aplicação de fertilizante orgânico obtido a partir de resíduos de frigorífico e a combinação com silício, sendo possível produzir feijão em sistema orgânico, alcançando produtividades semelhantes às obtidas no sistema convencional, desde que a cultura não sofra estresse hídrico.

\section{REFERÊNCIAS}

FREIRE, G.M., MEDEIROS, J.F., OLIVEIRA, F.A., AMÂNCIO, M.G., PONTES, N.C., SOARES, I.A.A., SOUZA, A.L.M. Aplicação de composto orgânico líquido via fertirrigação na cultura do meloeiro. Bioscience Journal., Uberlândia, v. 25, n.5, p. 49-55, 2009

PEREIRA, E.B. Efeitos da adubação orgânica com composto sobre a cultura do feijão (Phaseolus vulgaris L). Viçosa: UFV. 1984. 56 p.(Dissertação mestrado).

SANTOS, N.C. B. Potencialidades de Produção do feijão orgânico. Pesquisa \& Tecnologia. Disponível em: http://www.aptaregional.sp.gov.br Acesso em 04 de novembro de 2012.

SILVA, A. A. Potencialidade de recuperação de pastagem de Brachiaria decumbens fertilizada com cama de aviário e fontes minerais. 2005. 160 f. Dissertação (Dissertação de Mestrado) - Universidade Federal de Uberlandia. Faculdade de Medicina Vetrinaria. Uberlandia, MG, 2005. 